\title{
Deploying SiC BJTs in an 800-V Switched-Mode Power Supply for Hybrid \& Electric Vehicles
}

\author{
Andrew Hopkins \\ Department of Electrical and Electronic Engineering \\ University of Bristol \\ Bristol, UK \\ andrew.hopkins@bristol.ac.uk \\ William D. Drury \\ Hybrid \& Electronic Systems Business Unit \\ Ricardo UK Limited \\ Cambridge, UK \\ will.drury@ricardo.com
}

\author{
Neville McNeill \\ Department of Electronic and Electrical Engineering \\ University of Strathclyde \\ Glasgow, Scotland \\ neville.moneill@strath.ac.uk
}

\author{
Andrew Atkins \\ Ricardo Innovations Business Unit \\ Ricardo plc \\ Shoreham-by-Sea, UK \\ andrew.atkins@ricardo.com
}

\begin{abstract}
An SMPS for hybrid electric vehicle and electric vehicle applications is presented. The use of SiC BJTs in the primary-side switching circuitry is investigated. Practical deployment aspects are addressed. Particular attention is given to the design of the BJT base driver stage and a bespoke turn-on switching-aid circuit. Mathematical design calculations are not presented, but the proposed circuitry is demonstrated in a $1-\mathrm{kW}$ isolated-output DC-DC converter operating from $800 \mathrm{~V}$ and supplying $48 \mathrm{~V}$ at a switching frequency of $60 \mathrm{kHz}$. Full-load efficiency was evaluated at $93.3 \%$ using a calorimeter.
\end{abstract}

Keywords-Automotive, DC-DC, hybrid electric vehicle, SiC BJT, SMPS.

\section{INTRODUCTION}

Class 3 hybrid and electric vehicles for passenger car applications [1] are rated from $200 \mathrm{~V}$ to $800 \mathrm{~V}$. The $800-\mathrm{V}$ arrangements are currently related to electric buses, but passenger car developers [2] are actively pursuing these higher voltages in search of performance and efficiency. There is a consequent need for isolated-output on-board power converters to supply $48-\mathrm{V}$ and $12-\mathrm{V}$ rails for operating lowvoltage circuitry [3]. Low volume, low mass and high efficiency are desirable, as is the avoidance of forced-cooling systems. Wide bandgap (WBG) semiconductor devices [4] can facilitate high-efficiency power conversion and, of these, the SiC MOSFET has many attractive characteristics. However, concerns over gate oxide reliability [5] and the need to address crosstalk [6] can present challenges. A SiC JFET was evaluated in an 800-V SMPS in [7] where it was in a cascode configuration to address its normally-on characteristic. As an alternative, the $\mathrm{SiC} \mathrm{BJT}$ [8] may be considered, and has been used in converters such as those in [9] and [10]. However, less literature is available on its application in SMPS circuits. Although it needs a steady-state base drive current in the onstate [11] and does not have a reverse conducting capability, the $\mathrm{SiC} \mathrm{BJT}$ exhibits low inter-terminal capacitances at a given on-state resistance. This is essential for high-efficiency hard-switched voltage source converters (VSCs) where capacitive charging and discharging currents lead to power dissipation in the devices. Depending on the switching frequency, system-level benefits result by using a SiC BJT. The lack of the ability to conduct in reverse is not necessarily a disadvantage in SMPSs. This paper investigates the effectiveness of the $\mathrm{SiC} \mathrm{BJT}$ in an automotive power converter application. A high-performance BJT base driver circuit and a bespoke turn-on switching-aid circuit are presented.

\section{PROPOSED CIRCUITRY}

The dual-switch forward DC-DC converter topology was selected, Fig. 1, for evaluating the applicability of SiC BJTs and $\mathrm{SiC}$ diodes in the SMPS application here. Disadvantages of this topology include the relatively poor transformer winding utilization and a high peak voltage requirement in the output rectifier stage. However, apart from its simplicity, it exhibits the following benefits. Power devices switching on do so without having to charge the output capacitance of another active device in the same bridge-leg. Also, devices are not subjected to reapplied $\mathrm{d} v / \mathrm{d} t$ s due to other devices turning on. The diodes (D1 and D2) in the primary side only need to be rated to carry the transformer's decaying magnetizing current and a transient referred load current in its leakage inductances. A corollary is a low die size requirement with a consequent low junction capacitance. The unidirectional transformer core material excitation in the dual-switch circuit is less problematic, as, at switched-mode frequencies, this is often limited by core loss and not saturation considerations.

\section{A. Base Driver Requirements for the SiC BJT}

The principal functions of a base driver are to provide:

- $\quad$ high transient base currents for rapid switching; 
- $\quad$ small, but non-negligible on-state base currents as efficiently as possible;

- local floating power supplies for transistors with changing reference electrode potentials;

- protection against $\mathrm{d} v / \mathrm{d} t$-induced conduction ("crosstalk"). Normally a negative off-state base-emitter voltage is required for this. In the circuit in Fig. 1, reapplied $\mathrm{d} v / \mathrm{d} t \mathrm{~s}$ are not imposed on the devices. Nonetheless, a negative voltage is applied here to provide rapid switching and provide noise immunity.

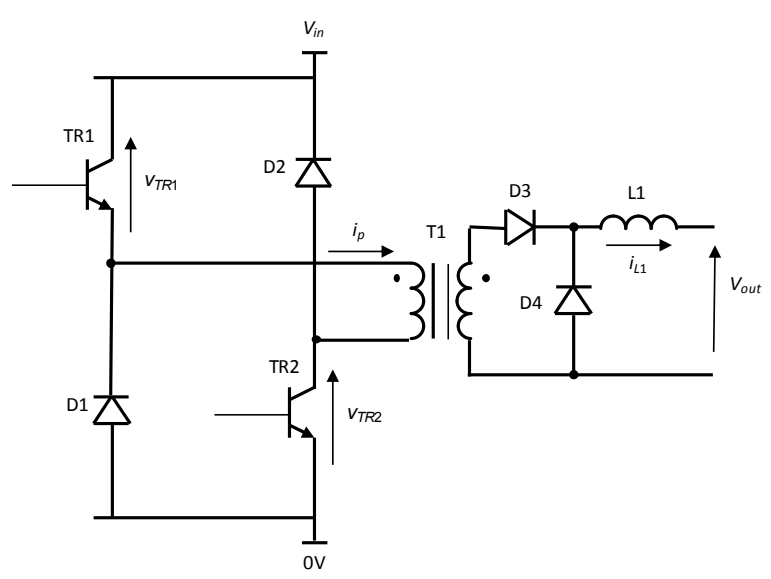

Fig. 1. Dual-switch forward converter with SiC BJTs.

\section{B. Discussion on Potential Base Driver Arrangements}

In isolated-output SMPSs, duty factors close to $100 \%$ are not usually encountered and, depending on the topology, they are typically limited to $50 \%$. This is the case with the dualswitch forward topology. Direct drive of the control electrodes (normally gates) via a transformer can often be used, for example, in [12] and the circuit using SiC JFETs in [7]. This can negate the need for local floating driver supplies by transmitting the energy needed to drive the control electrode and the signal through the same transformer. Whilst this technique is attractive as cost is reduced, it is discounted here as a transformer will introduce leakage inductances. This is problematic for fast switching with BJTs, as it is important that the BJT is driven via a local low-inductance loop [11].

Traditional bootstrapping and level-shifting techniques are also discounted because of the requirement for a negative offstate base-emitter voltage. This can be addressed, for example in [13], but circuit complexity is introduced. A negative offstate base-emitter voltage normally uses a negative voltage rail on the local gate or base drive supply. Alternatively, the transistor is driven differentially from two outputs from the same rail. In either case, base driving with level-shifting circuits is still problematic in terms of circuit complexity. Furthermore, the availability of drivers with a level-shifting capability of $1200 \mathrm{~V}$ is less than that of those rated at $600 \mathrm{~V}$, and a magnetically isolated solution was therefore preferred.

\section{Proposed Local Base Driver Circuit}

The proposed local driver circuit for each device is shown in an exemplifying form in Fig. 2. A single-rail supply with two output voltages acting differentially in antiphase is chosen to drive the base-emitter junction of the BJT for the following reasons. Firstly, it simplifies the driver supply. Where supplied from a flyback converter, only one transformer secondary winding and one rectifier diode are required for each local driver circuit. Secondly, the devices in the driver circuit only need to support a maximum voltage equal to $+V_{D R I}$, whereas with a three-wire supply they would have to support this and the negative voltage. This means that a wider range of commercially-available buffer ICs may be used. As in [14], a current transformer (CT) without discrete reset circuitry is included to supply a proportional regenerative base drive current. Further details of its operation in this mode are given in [14]. Whilst in [14] a negative base-emitter off-stage voltage is provided by a circuit using a third supply rail, the CT's operation is essentially the same in the circuit here.

TR5 acts as a switch to disconnect CT1 from the emitter of the power device when it is off. This prevents the CT's secondary winding from forming an unwanted DC short-circuit between the base driver's supply rails (denoted as " $0 \mathrm{~V}$ " and " $+V_{D R I}$ " in Fig. 2) during the BJT's off-time.

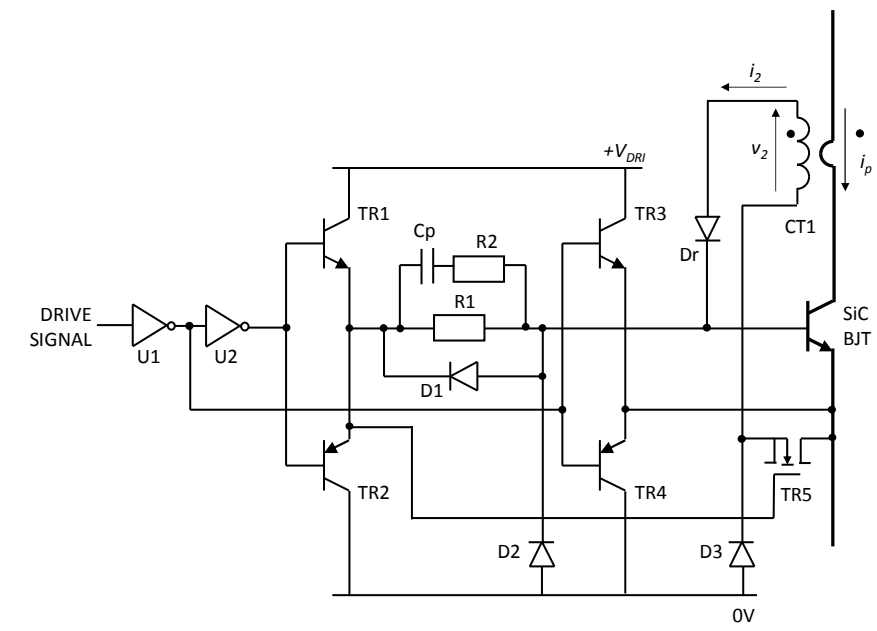

Fig. 2. Proposed local base driver circuit.

Fig. 3 highlights the operation of the circuit in Fig. 2 by showing the active components during the BJT's on- and offtimes. Fig. 4 shows the circuit in Fig. 2 realized with driver ICs replacing the discrete emitter follower bipolar transistor stages in Fig. 2. With respect to the circuits in Figs. 2 and 4, it is noted that TR5 or TR1 respectively is driven from the lowimpedance stage formed by TR $1 / 2$ or U3. Two of the circuits in Fig. 4 are needed to drive the two power devices in the application here and they are supplied with power from a single flyback converter using a transformer with two secondary windings. Another transformer, again with two secondary windings, supplies the drive signals. A feature of the SiC BJT is that its absolute maximum quoted negative base-emitter voltage is $30 \mathrm{~V}$ in the case of a device such as the GA10JT12- 
247 type. This is higher than a comparable SiC MOSFET's negative gate-source voltage which is typically less than $10 \mathrm{~V}$.

For reliability, opto-couplers were not used in the design proposed in this paper. The use of electrolytic capacitors was also avoided. The ferrite materials in the magnetic components all have specified minimum Curie temperatures exceeding $210^{\circ} \mathrm{C}$.
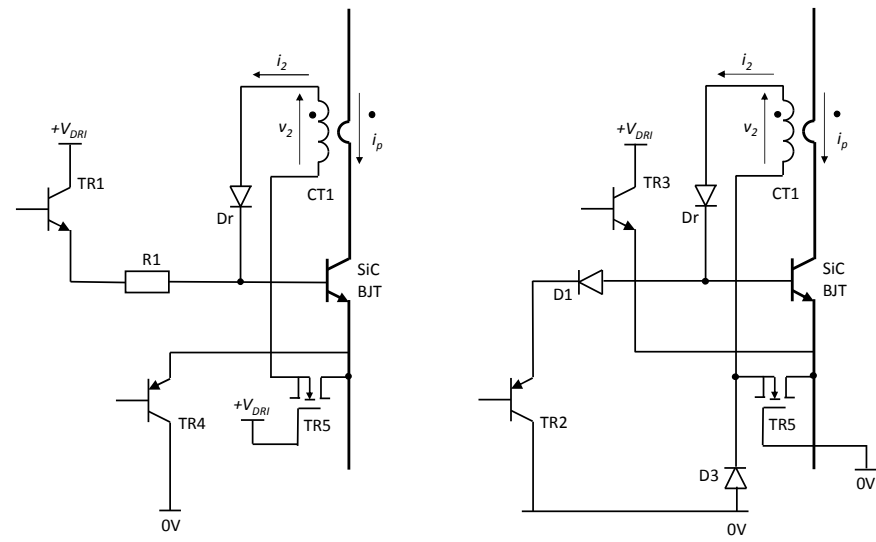

Fig. 3. Steady-state equivalent circuits formed by the circuit in Fig. 2. Left: when the BJT is on. Right: when the BJT is off. In the BJT's on-state TR5 is also on and allows CT1 to supply current into the base of the BJT. In the BJT's off-state TR5 is also off and prevents the CT1's secondary winding from applying a virtual short-circuit across the supply rails when the BJT's base-emitter junction is reverse-biased.

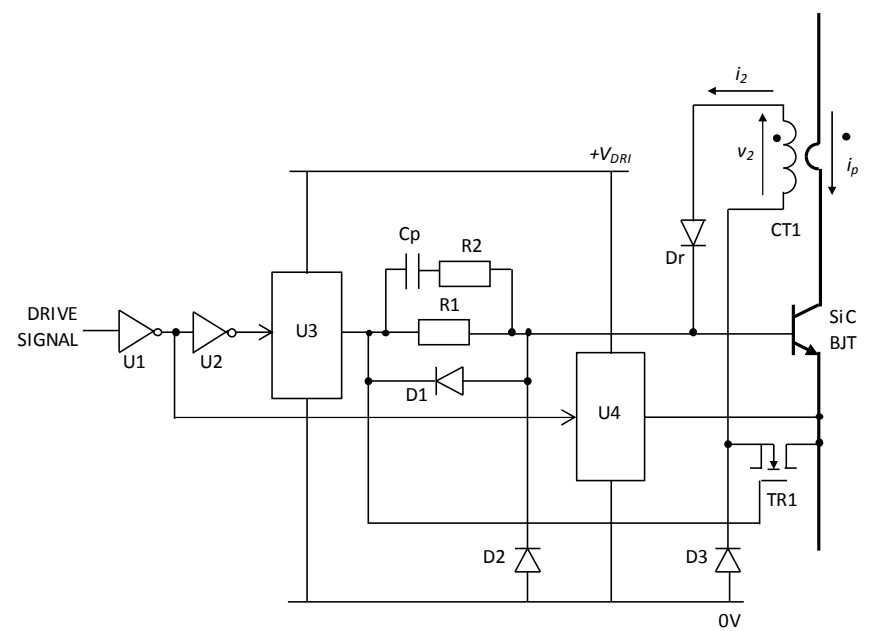

Fig. 4. Local base driver circuit from Fig. 2 realized with two driver ICs.

\section{Base Driver Signal Transmission and Floating Driver Power Supply Circuitry}

Fig. 5 shows the base driver signal transmission stage. Because the maximum duty factor is restricted to below $50 \%$, this readily allows implementation of simple magnetic isolation via T1 without the complexity or jitter encountered with carrier modulation schemes [15].
A potential problem with the basic scheme in Fig. 5 is that once the core flux has reset, T1's magnetizing inductance forms a resonant circuit with stray capacitances. A resultant voltage appears across the secondary winding or windings during the resonant action with the possibility of undesired multiple switching transitions. The clamping circuit highlighted in Fig. 5 was therefore included to mitigate this possibility. When TR1 is off, TR2 is turned on. When the flux decays to zero, Zener diode Dzl clamps the primary voltage in the normal way. However, when the voltage attempts to reverse it is now clamped to zero volts by TR2 via D4. The pull-down resistors, RL1 and RL2, were experimentally set at $500 \Omega$ to provide fast drive signal fall-times.

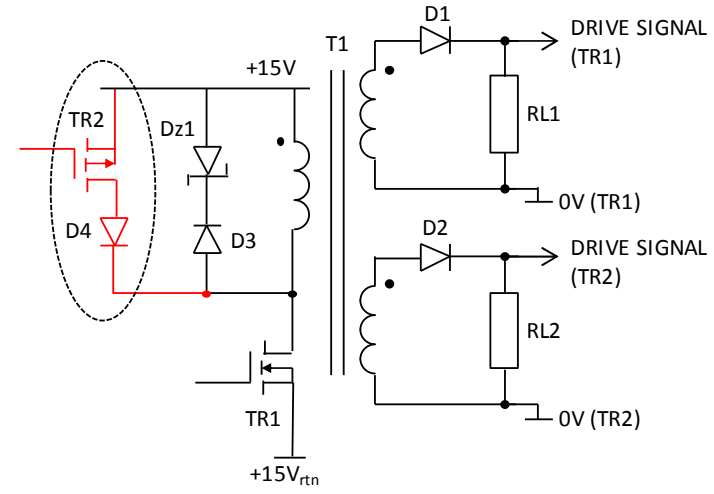

Fig. 5. Base driver signal transmission stage. The clamping circuit is highlighted within the dotted loop. (Dead-times are inserted between the gatedrive signals to TR1 and TR2 to avoid simultaneous conduction through D4.)

An identical toroidal magnetic component was used for transmission of power to the local floating base driver supplies, but it was connected in the flyback mode. The base driver power transmission circuit is shown in Fig. 6.

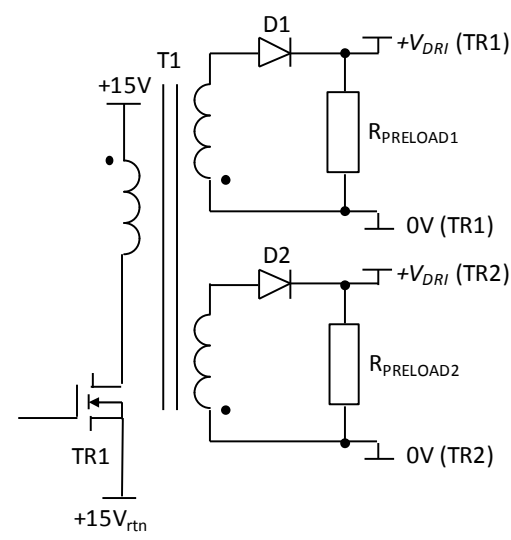

Fig. 6. Base driver power transmission stage using an identical magnetic component to that in Fig. 5, but connected for flyback operation. Rail decoupling capacitances are not shown.

A physically smaller core with a lower permeability (such as a gapped ferrite type) would normally be an optimal solution. However, the same type of transformer, as used for 
signal transmission, can be used here as the peak MMF occurring is such that core saturation does not result, even with an un-gapped core, yielding a reduced parts count. The power transmission transformer, TR1 in Fig. 6, was run at a constant duty factor of $50 \%$ and at a frequency of $180 \mathrm{kHz}$. This signal is at a frequency which is an integer multiple of the switching frequency, and was also synchronized to it. This was found to avoid jitter in the timing of the signals delivered to TR1/2. 1$\mathrm{k} \Omega$ resistors were connected across the rails of each local driver circuit to ensure that the discontinuous core flux mode is not entered at low load when no drive signal is applied to the BJTs and the quiescent power consumption is very small. (This is equivalent to the discontinuous current mode in the analogous non-isolated circuit, namely the buck-boost converter.) The circuit was run open-loop for simplicity, and allowing it to transition between the discontinuous and continuous core flux modes would result in an unpredictable voltage gain without feedback.

\section{E. Input Turn-On Switching-Aid Circuit}

A challenge with the circuit in Fig. 1 is that if the die area of diodes D1 and D2 is large, then high junction charges are drawn resulting in increased turn-on losses in TR1 and TR2. Diode manufacturers frequently quote the stored field energy in a diode reverse-biased at a given voltage. However, due to the non-linearity of the diode's junction capacitance, the resultant energy dissipated in an incoming hard-switched device is greater than this, being the associated co-energy. A small die area has the advantage that these charges are lower, but a slight increase in conduction losses is incurred and reliability may be compromised if the die area is too low.

A simple inductive turn-on switching-aid circuit with energy recovery was included, Fig. 7. As shown, inductor $L_{s}$ is interposed between the battery pack voltage, $V_{B A T T}$, and the input voltage to the SMPS in Fig. $1, V_{i n}$. The circuit has two effects. Firstly, at TR1/2 turn-on $L_{s}$ controls the charging currents into the diode junctions which are non-negligible. Secondly, TR1 and TR2 cannot turn-on instantaneously and $L_{s}$ reduces the turn-on losses by supporting some of the voltage which would otherwise be transiently supported by them. Combined with also slowing the rise of current into the devices, this reduces the volt-ampere time-integral appearing over them and reduces turn-on losses. The saturable inductor is well-suited for use with traditional power semiconductor devices, such as IGBTs. However, with the capacitive charging currents drawn by WBG devices, a linear inductor is preferred as it provides control of the charging current throughout the entire charging action. A linear snubber arrangement for use with silicon super-junction MOSFETs is presented in [16].

Snubber inductor reset and energy recovery is realized with an auxiliary reset winding, $N_{r}$. Using a winding for this purpose can be problematic due to high voltages appearing across the switching device or devices and the secondary side rectifier diode [17]. In [16] this problem is addressed by using a small auxiliary flyback converter to recycle snubber inductor energy back into the supply rail. However, a feature of the converter here is that a voltage sink in the form of a relatively lowvoltage $48-\mathrm{V}$ output rail is readily available for inductor reset with energy recovery. As this voltage is much less than the
$800-\mathrm{V}$ supply voltage, this enables a reset winding to be added to $L_{s}$ with relatively low aggregate voltage stresses appearing across the secondary side diode, $\mathrm{D}_{\mathrm{sec}}$ in Fig. 7 , and the power devices (TR1 and TR2 in Fig. 1). However, an RCD circuit similar to that in [18] was included to clamp over-voltages due to leakage inductances. This was formed from $R_{s}, C_{s}$ and $D_{s}$. $A$ local high-frequency decoupling capacitor, $\mathrm{C}_{\mathrm{d}}$, was included as shown in Fig. 7.

$N_{r}$ also acts at TR1/2 turn-off when it allows the current in $N$ to be commutated without causing an excessive over-voltage in $V_{i n}$. During this action, it again transfers stored energy in $L_{s}$ to the reset voltage sink, in this case, the $48-\mathrm{V}$ output rail.

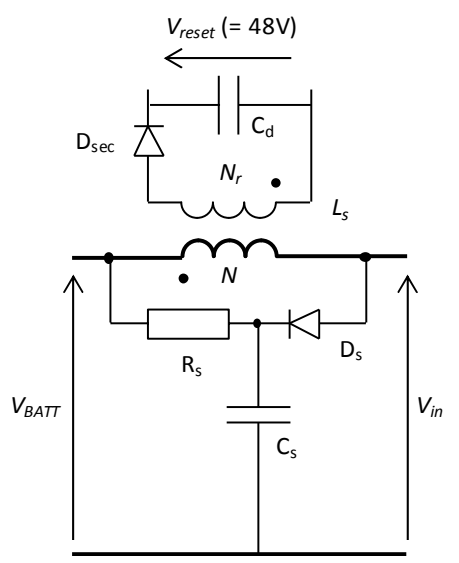

Fig. 7. Turn-on switching-aid circuit interposed between the battery pack voltage and the input voltage to the circuit in Fig. 1.

\section{EXPERIMENTAL HARDWARE DETAILS}

A circuit was developed using the dual-switch forward topology in Fig. 1 and is shown in Fig. 8. It was rated to operate from an $800-\mathrm{V}$ supply and was configured to drive a 1$\mathrm{kW}$ load at $48 \mathrm{~V}$. The switching frequency was $60 \mathrm{kHz}$. TR1 and TR2 were GA10JT12-247 BJTs. D1 and D2 were C4D10120A devices. TR1, TR2, D1, and D2 were mounted on the heatsink marked as $\mathrm{H} 1$ and located on the PCB.

Local decoupling of $V_{B A T T}$ was provided by six $1-\mu \mathrm{F}, 630-\mathrm{V}$ polypropylene capacitors connected in two series groups of three in parallel, giving an equivalent capacitance of $1.5 \mu \mathrm{F}$ and a voltage rating of $1260 \mathrm{~V}$, assuming ideal voltage sharing. The output filter capacitance was provided by three $10-\mu \mathrm{F}, 100 \mathrm{~V}$ polypropylene capacitors connected in parallel.

The base driver and switching-aid circuits were those in Figs. 4 to 7. Data are listed in Tables I to IV. For a reduced parts count, all the components in the base driver power transmission stage are also used in the signal transmission stage. Local decoupling capacitance was included across the base driver circuit supply rails as appropriate, but is not described here.

A custom-designed prototype planar transformer was procured for use in position $\mathrm{T} 1$ in Fig. 1. A non-planar choke 
based around gapped ferrite cores and a stranded conductor was designed for position L1 in Fig. 1.

The main objective in this paper was to investigate the performance of SiC BJTs in the SMPS's primary-side circuitry. For simplicity, the output rectifier stage, D3 and D4 in Fig. 1, used passive SiC Schottky diodes instead of synchronous rectification (SR). These diodes were mounted on the heatsink marked as $\mathrm{H} 2$ in Fig. 8. Two small 40-mm fans were mounted onto the rear of $\mathrm{H} 2$, blowing air into its fins. These were Sunon HA40101V4-000U-999 types. No direct forced-cooling of H1 or any other component was applied, and the heatsink style used for $\mathrm{H} 1$ is not optimized for naturally-cooled operation, having closely-spaced fins. It is noted that a 48-V SR arrangement for a high-efficiency SMPS output rectifier stage has been presented in [19].

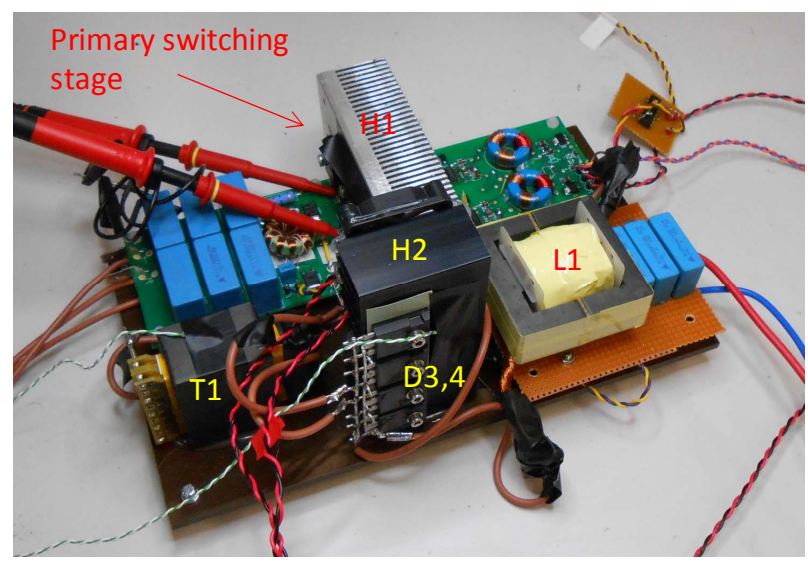

Fig. 8. Experimental hardware under test. The current transformers in each of the base driver circuits, Fig. 4, are located in PCB cutouts underneath heatsink H1. D3 and D4 on heatsink H2 are each composed of four SiC Schotty diodes in parallel. (Each package shown contains two diodes in a common-cathode arrangement.) There is significant stray inductance in the transformer connections. However, this is deemed to be beneficial here as it lumps with the transformer's leakage inductance to yield soft switching at TR1/2 turn-on.

The local floating base driver supply voltages, $+V_{D R I}$, in each case, were nominally set at $15 \mathrm{~V}$. As the low-side supply voltage was also $15 \mathrm{~V}$ and the flyback transformer in Fig. 6 was driven with a duty factor of $50 \%$, the transformer would ideally have a turns ratio of one. In practice, a slightly higher ratio was used to give some allowance for losses.

The three windings on the transformer used for transmitting the base drive power and signals were physically spaced apart from each other. Whilst this arrangement increases leakage inductances, the capacitances between the windings are minimized. This mitigates the flow of common-mode currents through these capacitances.

Unlike the wound component in Figs. 5 and 6 that was used in the base driver circuitry, the presence of common-mode capacitances between the windings on $L_{S}$ is not as critical. Consequently, $N$ and $N_{r}$ on $L_{s}$ were wound as a bifilar winding to maintain close coupling. This minimizes the associated leakage inductance and maximizes the energy transferred into the reset voltage sink, whilst also reducing the power dissipation in $R_{s}$. The insulation between all three windings on
T1 in Figs. 5 and 6 was arranged solely to be functional for experimental purposes here, and this was also the case with the insulation between $N$ and $N_{r}$ on $L_{s}$.

TABLE I. COMPONENT DATA: LOCAL BASE DRIVER CIRCUITS

\begin{tabular}{|l|l|}
\hline $\mathrm{R} 1$ & $500 \Omega$ (two vertically stacked $1-\mathrm{k} \Omega, 0805$ resistors) \\
\hline $\mathrm{R} 2$ & $11 \Omega$ \\
\hline $\mathrm{Cp}$ & $47 \mathrm{nF}$, ceramic \\
\hline $\mathrm{D} 1-3$ & $\mathrm{CD} 214 \mathrm{~A}-\mathrm{F} 150$ \\
\hline $\mathrm{Dr}$ & IDD03SG60C \\
\hline $\mathrm{CT} 1$ & $\begin{array}{l}\text { Ferroxcube TN13/7.5/5 core in 3C90 material with a two- } \\
\text { turn primary winding }(\mathrm{N} 1) . \mathrm{N} 2=60 \text { turns of one strand of } \\
0.25-\text { mm diameter copper wire. }\end{array}$ \\
\hline TR1 & NTF3055-100T1G \\
\hline $\mathrm{U} 1,2$ & One gate each from a 40106 hex inverting Schmitt trigger IC \\
\hline $\mathrm{U} 3,4$ & IXDN614SI driver IC \\
\hline
\end{tabular}

TABLE II. COMPONENT DATA: BASE DRIVER SIGNAL TRANSMISSION STAGE

\begin{tabular}{|l|l|}
\hline RL1, & $500 \Omega$ (two vertically stacked 1-k $\Omega, 0805$ resistors) \\
\hline D1-4 & 1N4148 \\
\hline Dz1 & MMSZ5250B \\
\hline T1 & $\begin{array}{l}\text { Epcos B64290L0632X087 core. N1 = 30 turns of one strand } \\
\text { of 0.25-mm diameter copper wire. N2 }=\mathrm{N} 3=33 \text { turns of one } \\
\text { strand of 0.2-mm diameter copper wire. }\end{array}$ \\
\hline TR1 & NTF3055-100T1G \\
\hline TR2 & FQT3P20TF \\
\hline
\end{tabular}

TABLE III. COMPONENT DATA: BASE DRIVER POWER TRANSMISSION STAGE

\begin{tabular}{|l|l|}
\hline $\mathrm{R}_{\text {PRELOAD } 1,2}$ & $1 \mathrm{k} \Omega$ \\
\hline $\mathrm{D} 1-2$ & $1 \mathrm{~N} 4148$ \\
\hline T1 & $\begin{array}{l}\text { Epcos B64290L0632X087 core. N1 = 30 turns of one } \\
\text { strand of 0.25-mm diameter copper wire. } \mathrm{N} 2=\mathrm{N} 3=33 \\
\text { turns of one strand of 0.2-mm diameter copper wire. }\end{array}$ \\
\hline TR1 & NTF3055-100T1G \\
\hline
\end{tabular}

TABLE IV. COMPONENT DATA: SWITCHING-AID CIRCUIT

\begin{tabular}{|l|l|}
\hline$L_{s}$ & $\begin{array}{l}\text { Micrometals T80-52 core. } N=\text { ten turns of 34 strands of 0.2- } \\
\text { mm diameter copper wire. } N_{r}=\text { ten turns of one strand of } \\
\text { TEX-FS 0.3-mm diameter triple-insulated winding wire. }\end{array}$ \\
\hline $\mathrm{C}_{\mathrm{s}}$ & $4.7 \mathrm{nF}, 2 \mathrm{kV}$, ceramic \\
\hline $\mathrm{C}_{\mathrm{d}}$ & $1 \mu \mathrm{F}$, plastic film \\
\hline $\mathrm{R}_{\mathrm{s}}$ & $220 \Omega, 2 \mathrm{~W}$, carbon film \\
\hline $\mathrm{D}_{\mathrm{s}}, \mathrm{D}_{\mathrm{sec}}$ & $\mathrm{C} 2 \mathrm{D} 05120 \mathrm{~A}$ \\
\hline
\end{tabular}

\section{EXPERIMENTAL RESULTS}

\section{A. Waveforms}

Key switching-frequency waveforms are shown in Fig. 9. Key switching transient waveforms at TR1/2 turn-on and turnoff are shown in Fig. 10. These are for operation at full power and at rated input and output voltages.

With respect to Figs. 9 and 10, it is seen that the steadystate voltage across TR2 at turn-on is pre-positioned at approximately half the rail voltage, at $400 \mathrm{~V}$. This is due to the clamping action of the output rectifier circuit during the offtime of TR1 and TR2. A reflected over-voltage of nominally $48 \mathrm{~V}$ is seen in $v_{T R 2}$ at TR2 turn off. This is due to the clamping action of $N_{r}$ on $L_{s}$ as the current in $N$ is commutated. With respect to Fig. 10, it is seen that, at TR1/2 turn-on, $V_{\text {in }}$ 
exhibits a transient fall. During this interval $L_{S}$ supports a proportion of $V_{B A T T}$ which would otherwise be applied across TR1 and TR2.

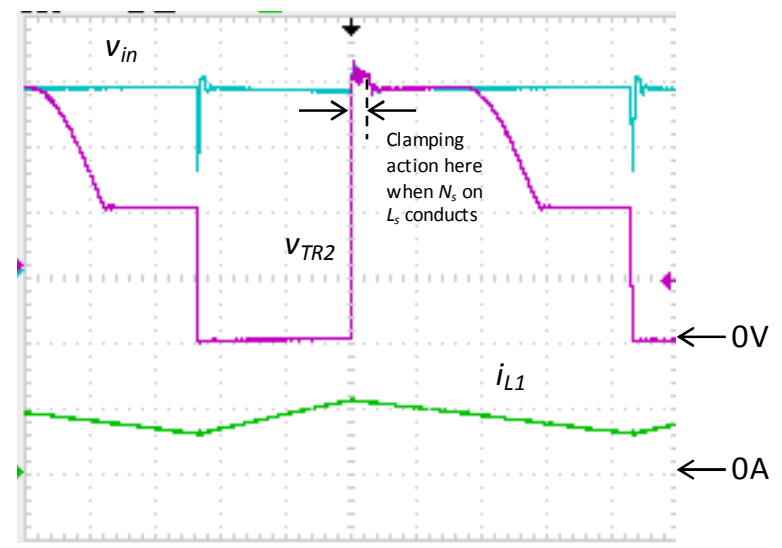

Fig. 9. Key switching-frequency waveforms. Scales: $v_{i n}=200 \mathrm{~V} /$ div., $v_{T R 2}=$ $200 \mathrm{~V} /$ div., $i_{L I}=25 \mathrm{~A} /$ div. Time scale $=2.5 \mu \mathrm{s} / \mathrm{div}$.
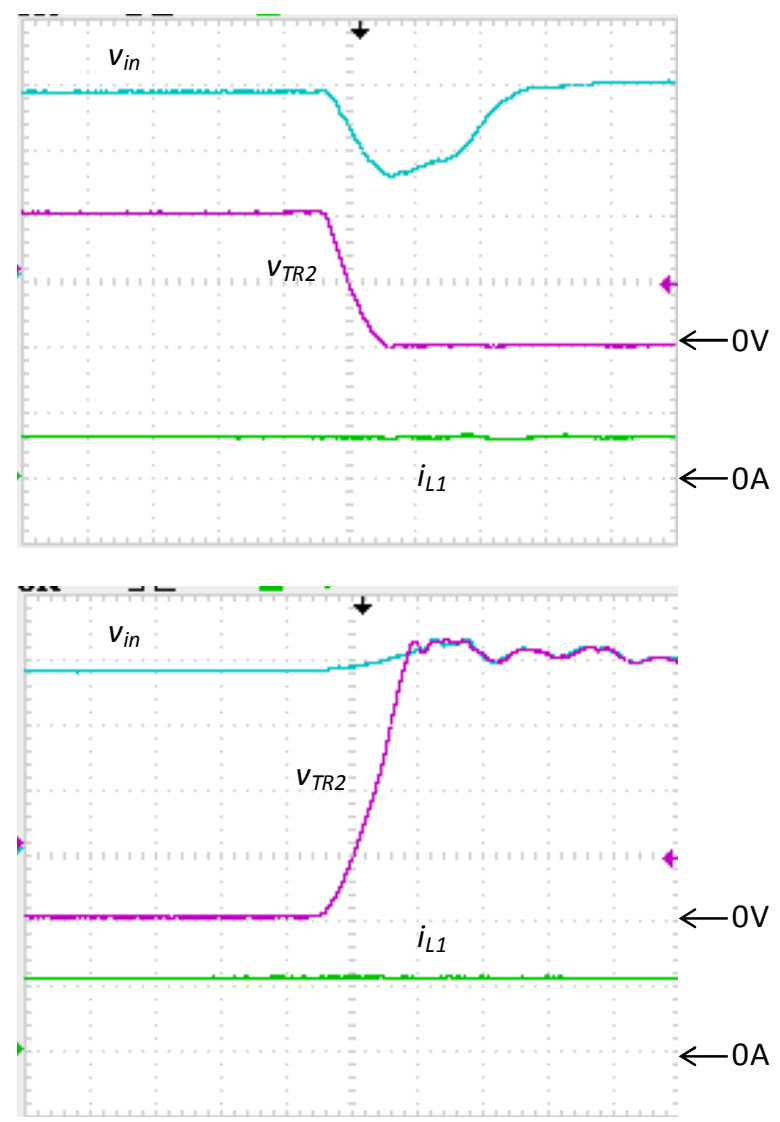

Fig. 10. Key waveforms at TR1/2 turn-on (upper set of traces) and turn-off (lower set of traces). Scales: $v_{i n}=200 \mathrm{~V} /$ div., $v_{T R 2}=200 \mathrm{~V} /$ div., $i_{L I}=25 \mathrm{~A} /$ div. Time scale $=50 \mathrm{~ns} / \mathrm{div}$.

\section{B. Thermal Behavior and Losses}

Fig. 11 shows a thermal photograph of the converter when running at full load on the horizontal surface as shown in Fig. 8. The circuit is in the hard thermal steady-state in Fig. 11 and the ambient temperature is taken as $21^{\circ} \mathrm{C}$ from the background reading in Fig. 11. No aberrant temperature rises were observed, and the highest temperature seen was that on the surface of $L_{s}$, at approximately $81^{\circ} \mathrm{C}$.

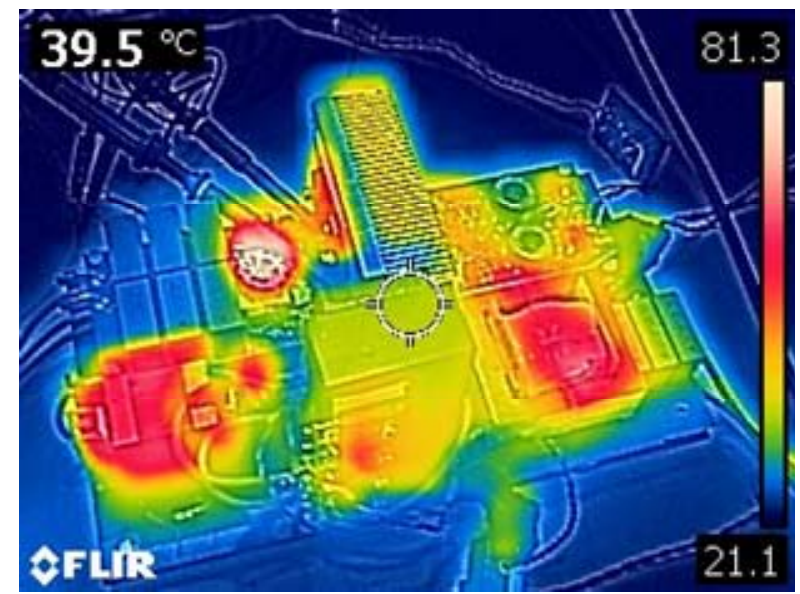

Fig. 11. Thermal photograph of circuit in Fig. 8. The temperature of H1 is registering as lower than its actual temperature due to the low emissivity of its surface. The actual temperature of $\mathrm{H} 1$ was measured at approximately $52^{\circ} \mathrm{C}$ with a thermocouple.

The converter was tested in a calorimeter as shown in Fig. 12. The output voltage and current were measured at $48.1 \mathrm{~V}$ and $20.9 \mathrm{~A}$, giving a power of $1.005 \mathrm{~kW}$. Losses were measured at $74.9 \mathrm{~W}$. The steady-state temperature inside the calorimetric chamber during this test was approximately $31^{\circ} \mathrm{C}$.

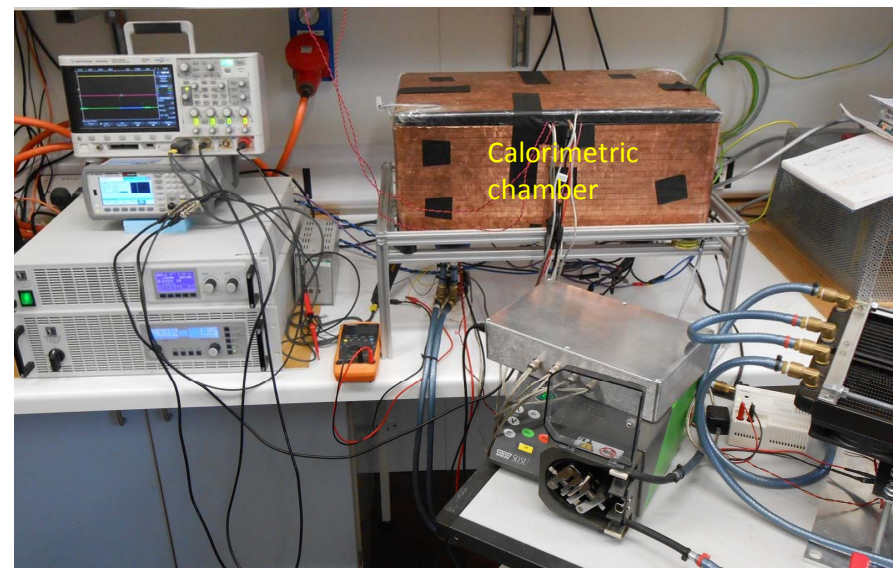

Fig. 12. Calorimetric set-up used for measuring efficiency.

Two adjustments were made when calculating efficiency. Firstly, there was approximately $0.3 \mathrm{~m}$ of conductor length located between the output terminals of the converter and the entry point in the calorimeter. The nominal cross-sectional area of this conductor was $2.5 \mathrm{~mm}^{2}$. Taking the effective length as 
$0.6 \mathrm{~m}$ and taking the resistivity of copper at $17.1 \times 10^{-9} \Omega \mathrm{m}$, a conductor resistance of $4.1 \mathrm{~m} \Omega$ was calculated. At a current of $21 \mathrm{~A}$, this gives a loss of $1.8 \mathrm{~W}$ which was subtracted from the loss of $74.9 \mathrm{~W}$ to yield a net loss of $73.1 \mathrm{~W}$. Secondly, the output voltage was measured at a point $1.0 \mathrm{~m}$ remote from the converter output terminals. The nominal cross-sectional area of this conductor was also $2.5 \mathrm{~mm}^{2}$. The cable loss is calculated as $6.0 \mathrm{~W}$, and this figure was added to the output power of $1.005 \mathrm{~kW}$ to give $1.011 \mathrm{~kW}$. An efficiency of $93.3 \%$ was therefore calculated.

When making adjustments, losses in the section of the input cabling within the calorimeter were neglected. The resistivity of copper was conservatively taken as that at $25^{\circ} \mathrm{C}$. In-line connectors were used within the calorimeter to interface with the outside world, and losses in these were neglected. Approximately $1.4 \mathrm{~W}$ of the measured power dissipation was attributable to the two fans located on $\mathrm{H} 2$, and this was included in the calculated loss value.

As with various other power semiconductor devices, the SiC BJT exhibits a potential thermal runaway condition. In the case of this device, its current gain falls with increasing temperature. In particular, it can enter the active region and develop a high collector-emitter voltage when it is on. This increases the conduction losses, in turn raising its temperature and further reducing its gain. It is therefore necessary to ensure that the combination of heatsink thermal resistance and base current is appropriate to avoid thermal runaway for the worstcase ambient temperature and operating conditions that will be encountered. The base current in the circuitry here is primarily determined by the turns-ratio of the CT used in the base driver circuits, and this ratio has to be set appropriately to avoid thermal runaway.

\section{DISCUSSION}

A qualitative description of the circuitry presented has been given. Several aspects of the circuit's performance may be investigated further and some of these are discussed here:

- The base driver performance can be investigated with the objective of attaining faster switching speeds. The values of components, in particular $\mathrm{Cp}$ and $\mathrm{R} 2$ in Fig. 4, may be optimized. It is noted that the signals from the differential output stages in Fig. 4 should ideally be in exact antiphase. However, a propagation delay is expected due to U2, and this consequently introduces a delay into the output signal produced by $\mathrm{U} 3$ with respect to that of $\mathrm{U} 4$. The effect on switching speeds may be assessed. Alternatives are to use a noninverting and an inverting driver IC with matched propagation delays in positions U3 and U4 respectively, or replace these with a single driver IC with complementary outputs (without dead-times). As described in Section IV, it is also necessary to determine the minimum safe base-drive current setting to avoid thermal runaway under worst-case conditions, and configure the base driver circuits appropriately.

- $1-\mathrm{k} \Omega$ pre-load resistances were included in the local floating base driver supplies to prevent the flyback base driver power transmission circuit, Fig. 6, from entering the discontinuous mode at light loads. At a voltage of $15 \mathrm{~V}$, these incur a total loss of $450 \mathrm{~mW}$. The objective is to maintain continuous core flux operation, thus yielding a predictable open-loop voltage gain without feedback. A cost-effective and more efficient alternative is expected to use a primaryside output voltage sensing scheme such as that in [20]. Similarly, $500-\Omega$ pull-down resistors were used in the base driver signal transmission circuit, Fig. 5 , in this case to provide short signal fall times. $15 \mathrm{~V}$ is also applied across them when TR1 and TR2 are signaled on. At a duty factor of $40 \%, 360 \mathrm{~mW}$ is dissipated. Whilst the total power consumption of $810 \mathrm{~mW}$ in the pre-load and pull-down resistors described here may appear low, it represents over $8 \%$ of the loss budget if a $99 \%$-efficiency primary-side switching stage is being targeted.

- $\quad$ The input switching-aid circuit using the inductance $L_{s}$ in Fig. 7 removes losses from TR1 and TR2. However, the leakage inductance of $\mathrm{T} 1$ in Figs. 1 and 8 also provides a desirable turn-on snubbering effect. The necessity or otherwise, of incorporating an input switching-aid circuit can be investigated, along with optimization of T1's leakage inductance.

- The BJTs used have a quoted on-state resistance of $100 \mathrm{~m} \Omega$ at $25^{\circ} \mathrm{C}$. A corollary of a low on-state resistance is high inter-terminal capacitances with consequent losses associated with their charging and discharging during switching transients. Conversely, whilst a higher on-state resistance introduces higher conduction losses, capacitive losses are expected to be lower. Notwithstanding cost issues, further work is required to establish the optimum on-state resistance for further improving efficiency in this application. Similarly, the die size of the diodes in the primary stage may be addressed.

- The heatsinks (H1 and H2) were essentially nonoptimized placeholders and small fans were used to cool the output rectifier stage on $\mathrm{H} 2$. Further work will also include developing hardware without forced cooling. This will include optimized heat dissipation and introducing SR in the output rectifier stage. In the dual-switch forward converter, this stage has to support a higher voltage than is the case with topologies such as the full-bridge converter in [7]. It is consequently necessary to use higher-voltage rated MOSFETs in it with different capacitance and reverse-recovery characteristics.

\section{CONCLUSION}

An isolated-output power converter for hybrid electric vehicle applications using $\mathrm{SiC}$ BJTs has been presented. The converter operates from an input voltage of $800 \mathrm{~V}$ and supplies $48 \mathrm{~V}$ at an output power of $1 \mathrm{~kW}$. The switching frequency was $60 \mathrm{kHz}$ and the full-load efficiency was measured at $93.3 \%$. The focus of this paper has been on the primary-side switching circuitry. Practical deployment issues have been addressed in a 
qualitative manner, including the use of ancillary magnetic circuitry. It is concluded that the $\mathrm{SiC} \mathrm{BJT}$ is effective in this application and yields system-level benefits. Whilst its need for a steady-state base drive current in the on-state may appear to be inconvenient, compared to the $\mathrm{SiC}$ MOSFET its drive requirements are robust. Firstly, it does not have to have a carefully-defined control voltage applied in its on-state. Secondly, it can withstand a high negative off-state control voltage across its base-emitter junction. Further work will include the development of secondary-side circuitry with synchronous rectification, and addressing control circuit, packaging and EMC requirements.

\section{ACKNOWLEDGMENT}

The funding for the project entitled "High efficiency power converter for hybrid electric vehicles" obtained from an EPSRC Impact Acceleration Account grant (No. $\mathrm{EP} / \mathrm{K} 503824 / 1$ ) held at the University of Bristol is acknowledged. The work of Dr Nick Simpson of the University of Bristol in developing the calorimeter and making it available for experimentation is acknowledged.

\section{REFERENCES}

[1] www.eurobat.org/sites/default/files/rev of battery executive web 1.pd f, online, accessed January 2017.

[2] www.caradvice.com.au/383646/volkswagen-group-to-replicate-batterytechnologies-across-models-and-introduce-800v-ev-system, online, accessed January 2017.

[3] K. Bae-Sung, K. Hee-Jun, J. Chunfeng, and H. Dong-Young, “A digital controlled DC-DC converter for electric vehicle applications", Proceedings, 2011 International Conference on Electrical Machines and Systems (ICEMS), Beijing, China, August 2011.

[4] C. DiMarino, R. Burgos, and D. Boroyevich, "High-temperature silicon carbide: characterization of state-of-the-art silicon carbide power transistors", IEEE Industrial Electronics Magazine, pp. 19-30, September 2015.

[5] R. Ouaida et al., "Gate oxide degradation of SiC MOSFET in switching conditions", IEEE Electron Device Letters, Vol. 35, No. 12, pp. 12841286, December 2014

[6] S. Jahdi et al., "Temperature and switching rate dependence of crosstalk in Si-IGBT and SiC power modules", IEEE Transactions on Industrial Electronics, Vol. 63, No. 2, pp. 849-863, February 2016.

[7] J. Dodge, "SiC JFET cascode enables higher voltage operation in a phase shift full bridge DC-DC converter", Proceedings, PCIM Europe 2016, Nuremberg, Germany, pp. 484-491, May 2016.

[8] R. Singh, S. Sundaresan, E. Lieser, and M. Digangi, "1200 V SiC "super" junction transistors operating at $250{ }^{\circ} \mathrm{C}$ with extremely low energy losses for power conversion applications", Proceedings, $27^{\text {th }}$ Annual IEEE Applied Power Electronics Conference and Exposition (APEC 2012), Orlando, FL, USA, pp. 2516-2520, February 2012.

[9] G. Calderon-Lopez, A. J. Forsyth, D. L. Gordon, and J. R. McIntosh, "Evaluation of SiC BJTs for high-power DC-DC converters", IEEE Transactions on Power Electronics, Vol. 29, No. 5, pp. 2474-2481, May 2014.

[10] S. Safari, A. Castellazzi, and P. Wheeler, "Experimental and analytical performance evaluation of $\mathrm{SiC}$ power devices in the matrix converter", IEEE Transactions on Power Electronics, Vol. 29, No. 5, pp. 2584-2596, May 2014.

[11] D. Peftitsis and J. Rabkowski, "Gate and base drivers for silicon carbide power transistors: an overview", IEEE Transactions on Power Electronics, Vol. 31, No. 10, pp. 7194-7213, October 2016.

[12] D. M. Van de Sype, A. P. Van den Bossche, J. A. Melkebeek, and J. Maes, "Gate drive circuit for zero-voltage-switching half- and fullbridge converters", Conference Record, $36^{\text {th }}$ Industry Applications Conference, Chicago, IL, USA, pp. 2151-2158, September/October 2011.

[13] S. Park and T. M. Jahns, "A self-boost charge pump topology for a gate drive high-side power supply", Proceedings, $18^{\text {th }}$ IEEE Annual Applied Power Electronics Conference and Exposition, Miami Beach, FL, USA, pp. 126-131, February 2003.

[14] N. McNeill, B. Jin, and X. Yuan, "Proportional regenerative base driver circuit with negative off-state voltage for $\mathrm{SiC}$ bipolar junction transistors", Proceedings, $8^{\text {th }}$ IET Power Electronics, Machines and Drives Conference (PEMD 2016), Glasgow, Scotland, April 2016.

[15] F. G. Turnbull, "A carrier-frequency gating circuit for static inverters, converters and cycloconverters", IEEE Transactions on Magnetics, Vol. Mag-2, No. 1, pp. 14-17, March 1966.

[16] N. McNeill, P. Anthony, and N. Oswald, "Ultra-high efficiency machine drive inverter using super-junction MOSFETs", Proceedings, $7^{\text {th }}$ IET Power Electronics, Machines and Drives Conference (PEMD 2014), Manchester, UK, April 2014.

[17] X. He, B. W. Williams, S. J. Finney, and T. C. Green, "Snubber passive lossless turn-on snubber energy recovery in high frequency power converters", Proceedings, 1993 International Conference on Industrial Electronics, Control, and Instrumentation (IECON '93), Vol. 2, pp. 790795, November 1993.

[18] L. Zhu, "A novel soft-commutating isolated boost full-bridge ZVSPWM DC-DC converter for bidirectional high power applications", IEEE Transactions on Power Electronics, Vol. 21, No. 2, pp. 422-429, March 2006.

[19] U. Badstuebner, J. Biela, and J. W. Kolar, “An optimized, 99\% efficient, $5 \mathrm{~kW}$, phase-shift PWM DC-DC converter for data centers and telecom applications", Proceedings, 2010 International Power Electronics Conference (IPEC), pp. 626-634, June 2010.

[20] Z. Ye, "Micropower isolated flyback converter with input voltage range from 6V to 100V", Design Note 509, Linear Technology, www.linear.com, accessed December 2016. 